\title{
Left Atrial Myxoma
}

\section{An Ultrastructural Study}

\author{
P. Chopra, M.D. and V.K. Sharma, M.D., D.C.P.
}

\section{SUMMARY}

Electron microscopic observations of 4 excised cardiac myxomas were made. All were present in the left atrium and all but one had a stalk. The hearts were otherwise normal. Several types of mesenchymal cells in varying stages of differentiation were identified. Cells having some features of smooth muscle, fibroblasts, and endothelium were observed. Some cells having features of both smooth muscle and fibroblasts namely, myofibroblasts were also encountered. Macrophages, lymphocytes and plasma cells were also seen in small numbers. Hematopoictic foci and calcification were not seen in any of our cases. Ultrastructurally, fine electron dense granules and only stray collagen fibres were noted in the matrix.

Myxomas possibly represent either hyperplasia or a true neoplasm of the subendocardial multipotential cells that are capable of differentiating into various types of mesenchymal elements.

\section{Additional Indexing Words:}

Cardiac myxoma Multipotential mesenchymal cells Hyperplasia Myofibroblast

T TISTOGENESIS of cardiac myxomas has been a subject of much debate.

1 The two controversial views are whether these are thrombi or neoplasms. Several reports based on light microscopy, histochemistry, and ultrastructural studies favour their neoplastic nature. ${ }^{11-9)}$ Salyer and coworkers, however, have postulated the thrombogenic nature of myxomas. ${ }^{10), 11)}$ In an earlier report ${ }^{12}$ ) we have described the gross, light microscopic and histochemical features of cardiac myxomas. Since then an additional case has been subjected to surgery. This communication is based on a detailed electron microscopic evaluation of 4 cases in an attempt to define the histogenesis of this entity.

From the Department of Pathology, All India Institute of Medical Sciences, New Delhi 110029, India.

Address for reprint: Dr. P. Chopra, Assistant Professor, Department of Pathology, All India Institute of Medical Sciences, Ansari Nagar, New Delhi 110029, India.

Received for publication July 14, 1982. 


\section{Materials and Methods}

Eight cardiac myxomas were surgically excised between the years 1976 and 1981. Four cases were subjected to electron microscopy. Small pieces of the excised lesion were taken from multiple sites and cut into $1 \mathrm{~mm}^{3} \mathrm{seg}-$ ments and processed. After fixation for 2 hours in $1 \%$ osmium tetroxide in veronal buffer, the pieces were dehydrated through ascending grades of alcohol and embedded in Epon. Sections were cut on a Reichert ultratome, after which they were stained with uranyl acetate and lead hydroxide and examined under a Philips 300 electron microscope operated at $60-80 \mathrm{kv}$. Thick sections (lu) from each block were stained with $0.2 \%$ toludine blue and examined under the light microscope in order to select the area for electron microscopic examination.

Small pieces of myxomas were also fixed in $10 \%$ buffered formalin and processed conventionally for light microscopy. Five $\mu$ thick paraffin sections were stained with hematoxylin and eosin. On selected sections from all cases, phosphotungstic acid hematoxylin (PTAH), Masson Trichrome, Verhoff's Van Gieson (VVG), Wilder's reticulin, alcian blue, periodic acid shiff (PAS), iron and toludine blue stains were also used.

\section{Results}

Patients ranged in age from 13 to 48 years. There were 5 males and 3 females. All the masses were located in the left atrium in the region of the fossa ovalis. Patients were NYHA functional class I to class IV and the duration of their complaints ranged from 6 to 36 months (Table I).

All the excised growths were lobulated, greyish pink and gelatinous, varying in dimensions from $4.5 \times 3.5 \times 1.5 \mathrm{~cm}$ to $8 \times 5 \times 2 \mathrm{~cm}$, with the weight varying from 19 to $25 \mathrm{Gm}$. All but one had a stalk which varied in thickness and length from $0.5 \mathrm{~cm}$ to $2 \times 1.5 \times 0.2 \mathrm{~cm}$. The cut surface was smooth or bosselated and was variegated red, grey and yellow. All the lesions were soft and mucoid.

Light microscopy revealed essentially similar features in all the myxomas. The cells were round or polygonal, arranged singly, in small groups, in syncytium, or in a gland-like manner around thin walled vascular channels in scant to abundant mucopolysaccharide rich stroma. Hemosiderin laden macrophages, a few plasma cells and lymphocytes were also encountered. No hematopoietic foci or calcification was observed in any of the cases.

Electron microscopic observations

Findings were more or less identical in all 4 cases. Cellularity was 


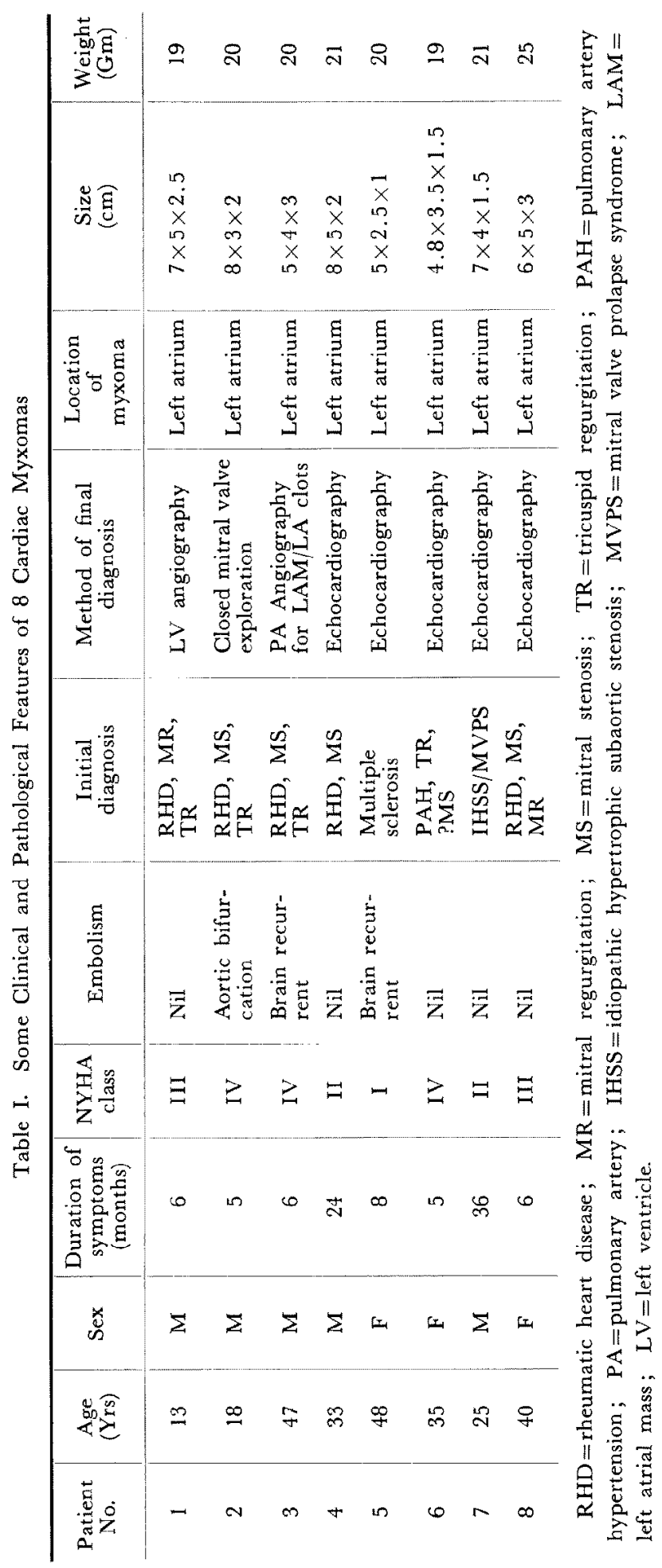




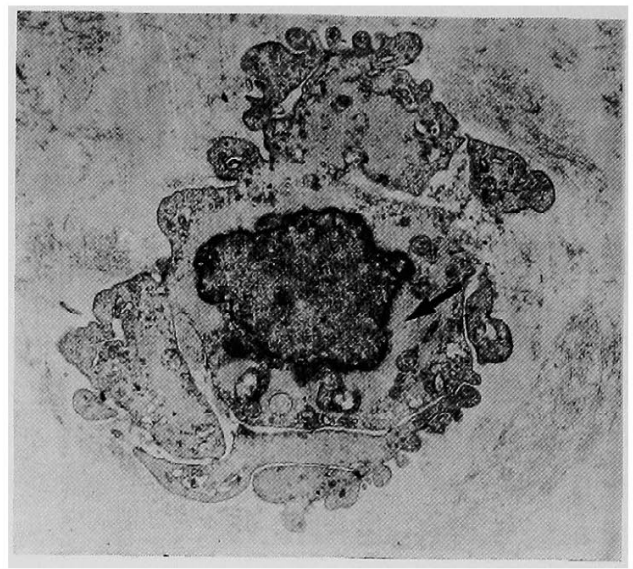

Fig. 1. A myxoma cell. Note the numerous outpouchings of the cell membrane. Nucleus has irregular outlines and chromatin is condensed at the membrane. Cytoplasmic organelles are very few and the cytoplasm is largely occupied by fine microfilaments (arrow). The matrix shows a few collagen fibres and some granular material. $\times 4,800$

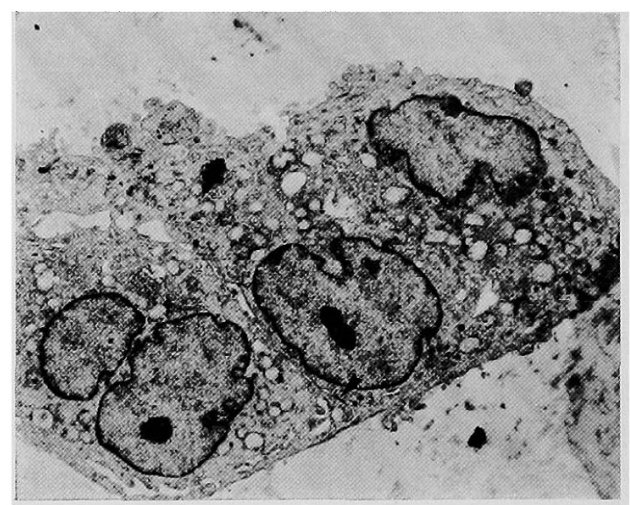

Fig. 2. A group of 4 myxoma cells. No definite cell outlines are seen. Small intercellular junctions (zonulae adherentes) are present (arrow head). Nuclei exhibit prominent identations of the nuclear membrane with focal condensations of nuclear chromatin. Nucleoli are prominent. Moderate numbers of cytoplasmic organelles are present. $\times 3,000$

sparse and the cells were dispersed in an abundant stroma composed of fine electron dense granules and occasional collagen fibres. The cells were present either singly or in small groups varying from 3-7 in number that were closely apposed (Figs. 1, 2). The cells were round to ovoid and polyhedral with irregular outlines. Most of the cells had prominent villous projections of the cell membrane with some interdigitations with the neighouring cells (Figs. 1-3). Intercellular contact between cells that occurred in groups consisted of areas in close apposition to the plasma membrane of adjacent cells. These regions, that is, the zonulae adherentes constituted only a small fraction of the 
total area of contact (Fig. 2). Nuclei were round to ovoid and in some cells even elongated (Figs. 1, 2, 5). The nuclear membranes at times showed deep indentations (Fig. 2). Nuclear chromatin varied considerably in amount and distribution and was moistly seen to be condensed along the inner nuclear membrane (Figs. 1, 2). Nucleoli were prominent (Fig. 2). Cells that contained only a few organelles had large nuclei whereas those that had moderate to abundant cytoplasmic organelles, had small, round to ovoid somewhat eccentric nuclei.

Electron microscopic features resembling smooth muscle cells, fibroblasts and endothelial cells were observed. Myofibroblasts, i.e., cells having features of both muscle cells and fibroblasts, were also identified. The following cell types were encountered and are described below according to the type and distribution of cytoplasmic organelles.

1. This cell type was most frequently encountered. The cellular membrane was thrown into prominent folds (Fig. 1). Cytoplasmic organelles were few and unevenly distributed. The most striking features in these cells were the numerous microfilaments present in parallel bundles which crisscrossed in various directions (Fig. 1). These were seen around the nucleus and in between organelles thus pushing the latter towards the periphery. These filaments lacked periodicity and resembled myofilaments. At places the filaments were condensed along their course. These were designated as filamentous dense bodies (FDB). In addition, the cells showed few degenerated mitochondria, occasional rough endoplasmic reticulum (RER), myelin figures, and variable numbers of pinocytotic vesicles. Lysosomes varied in size and number. They were limited by single membranes and contained an electron dense matrix. Some of them had iron particles within them. Smooth endoplasmic reticulum (SER), golgi apparatus and ribosomes were lacking in this type. These cells had several features resembling myogenic cells.

2. Another type of cell commonly encountered had a cell membrane with identical features to the cell described above. The extensive microvilli and the cell membrane were seen as membrane-bound spaces within the periphery of the cell. Pinocytotic vesicles were abundant. Moderate number of cytoplasmic organelles were identified (Fig. 3). These were mitochondria of varying sizes, myelin figures, few RER profiles, lysosomes and ribosomes. A number of mitochondria revealed crystalline inclusions (Fig. 3) within them. Few to moderate numbers of microfilaments were also present within these cells. No lipid droplets, basement membranes or tight junctions were seen. These cells exhibited no tendency to form or line vascular channels. In the absence of these features these cells were not typical of endothelial cells al- 


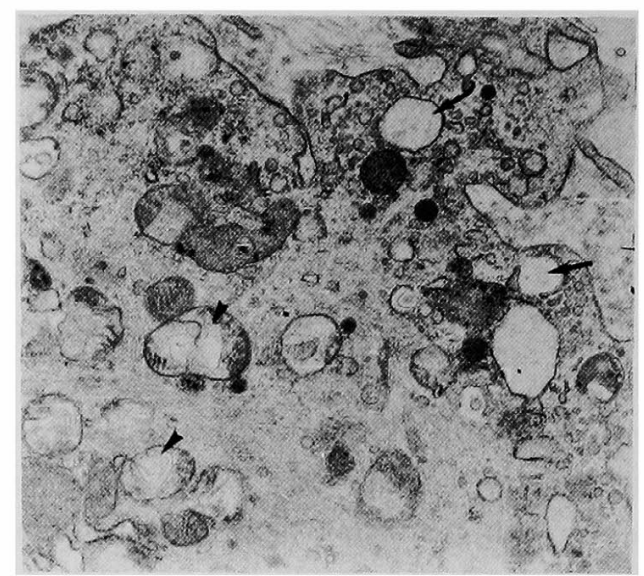

Fig. 3. Numerous pinocytotic vesicles beneath the cell surface of a myxoma cell are seen. Mitochondria having crystalline inclusions within them are present (arrow head). Membrane bound spaces are also seen near the cell surface (arrow). A large number of microfilaments fill the cytoplasm. A few collagen fibres are noted in the matrix. $\quad \times 16,500$

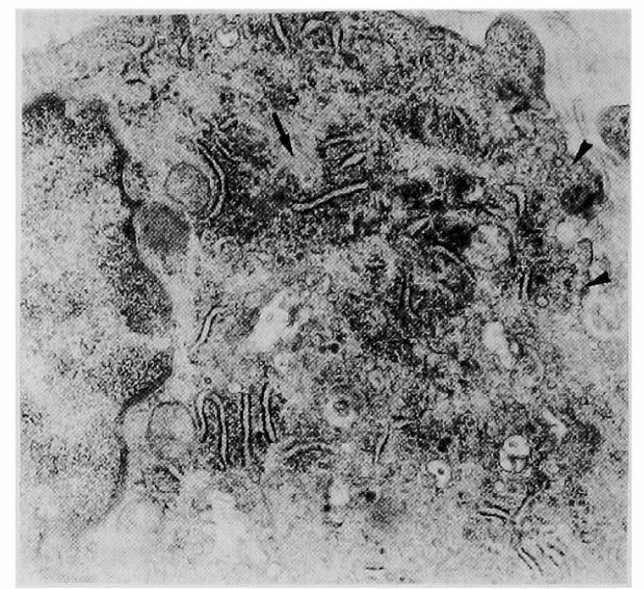

Fig. 4. A myxoma cell showing numerous cytoplasmic organelles. A number of RER profiles, free fibosomes and a few mitochondria are seen. Pinocytotic vesicles are present below the cell surfacc (arrow head), and microfilaments (arrow), well marked in the perinuclear region are also present. $\times 16,500$

though they possessed some of their features.

3. The third cell type not infrequently present had several features of a fibroblast. These were elongated cells with large ovoid nuclei. The cytoplasm showed prominent RER profiles and free ribosomes. Golgi complexes were also identified, Mitochondria were few to moderate in number and few pinocytotic vesicles were also present. Microfilaments were seen around the nucleus and beneath the cell membrane. No collagen was iden- 


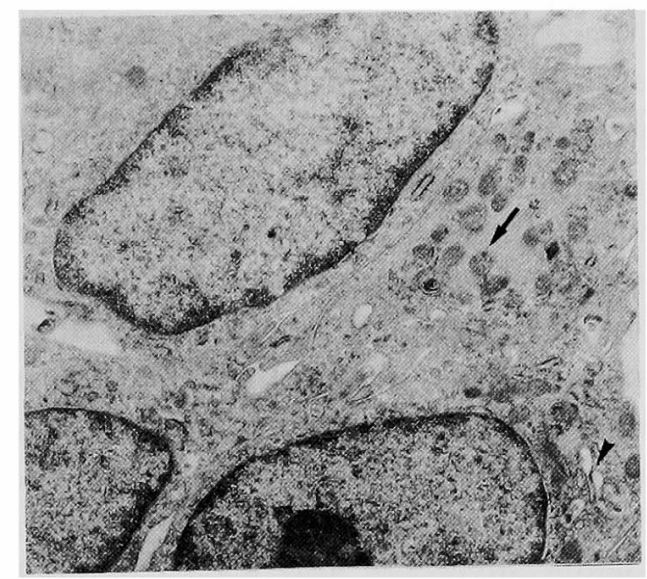

Fig. 5. A close up of 3 myxoma cells. Cytoplasmic organelles are moderate in number. Mitochondria, free ribosomes, microfilaments (arrow) and golgi apparatus (arrow head) are also identified. Cell junctions are ill defined. Nuclei are elongated and ovoid. $\times 12,600$

tified in proximity to these cells (Figs. 4, 5).

Many cells had features of both smooth muscle cells and fibroblast and were thus labelled as myofibroblasts. In addition, macrophages, some of which contained hemosiderin, and a few lymphocytes and plasma cells were also identified.

\section{DisGussion}

A difference of opinion has always existed regarding the histogenesis of cardiac myxomas. Several histochemical and electron microscopic studies have shown conclusively that these are true neoplasms. ${ }^{2,4)-99,13), 14)}$ On the other hand, a group of workers have postulated that myxomas arise from mural thrombi. ${ }^{10), 11)}$

Several types of variably differentiated cells, such as macrophages, endothelial, fibroblast-like and smooth muscle cells were encountered in the present study. Most of these cells contained numerous thick and thin filaments. Cytoplasmic filaments have now been described in a large number of normal and abnormal mesenchymal cells, ${ }^{15)-18}$ ) thus making it difficult to differentiate the various types of cells.

In the first electron microscopic study, Zuidema et al ${ }^{19)}$ observed sparse numbers of elongated primitive-appearing, mesenchyme-like cells embedded in an abundant matrix. In addition to the usual cytoplasmic organelles, the tumour cells contained numerous membrane-limited droplets resembling secretion droplets. The latter was not observed in any of the 4 cases under 
study. Similar to the present study, Matsuyama and Ooneda ${ }^{5}$ ) observed cells having cytoplasmic filaments of unspecified diameters, numerous tubules of RER, ovoid dense areas, interdigitations and collagen and elastic fibres in the stroma. They also observed hematopoietic foci in haemorrhagic areas, and a few cross striated tadpole shaped tumour cells that resembled those seen in embryonal botryoid rhabdomyosarcoma. In contrast to this, we did not observe any hematopoietic foci and cross striated fibres. Silverberg and $\mathrm{Kay}^{14)}$ and Fine ${ }^{13}$ ) observed in a fine granular stroma polyhedral cells that contained abundant RER, secretory vacuoles and moderate numbers of small mitochondria. Neither of them described cytoplasmic filaments. Fine $^{17)}$ concluded that myxomas are slow growing tumours that arise from mesenchymal cells, while Silverberg and $\mathrm{Kay}^{14)}$ pointed out that they are endothelial in origin.

Merkow et $\mathrm{al}^{6)}$ observed similar electron microscopic features as reported by us and others. ${ }^{3 /-6), 91,19), 201}$ They considered the cytoplasmic filaments as being in the same size range as those of smooth muscle cells, and believed, therefore, that myxoma cells should be classified as a myoid type of endocardial (endothelial) or subendothelial cell. In a recurrent left atrial myxoma, Kelly and Bhagwat ${ }^{7)}$ found a single cell type, which they considered endothelial in character. These cells had prominent nucleoli, basement membranes, centrioles, and peculiar intralysosomal crystalloids in addition to features similar to those described in other cardiac myxomas. They regarded this tumor as having been derived from endocardial reserve cells.

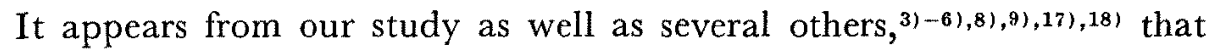
myxomas contain several types of mesenchymal cells in varying stages of differentiation which resemble muscle cells, fibroblasts, endothelial cells and cells having features of both smooth muscle and fibroblasts (myofibroblasts). Ultrastructural examination of the normal endocardium shows the presence of several of the mesenchymal cells outlined above. ${ }^{21)}$ A prominent feature of the cells constituting the myxomas was the presence of microfilaments within the cytoplasm. Filaments, however, have been described in a large variety of normal as well as tumour cells. ${ }^{18)}$ These filaments possibly form a cytoskeleton that provides structural support to the cells. Immunofluorescence studies using antibodies against smooth muscle myosin and actomysin have shown the presence of these proteins in the atrial endocardium and capillary endothelium. ${ }^{22)}$

Myxomas occur in otherwise normal hcarts and are invariably located on the left side of the atrial septum. Experimentally, ${ }^{23)}$ thrombi when implanted in the heart undergo a progressive reduction in size until they are completely organized. Myxomas in tissue culture have distinct morphologic 
differences from thrombi. ${ }^{24)}$ Biochemical analyses have shown that myxomas contain chondriotin 4 and/or 6 sulphates predominantly and that dermatan sulphate is absent. ${ }^{25)}$ The latter is present in thrombi and this observation suggests that myxomas are neoplasms rather than thrombi.

The presence of mesenchymal cells in intermediate stages of differentiation as seen ultrastructurally suggests that myxomas may represent a neoplasm, hyperplasia or a hamartoma. The observations by several authors and by us have demonstrated cells resembling smooth muscle cells, fibroblasts, endothelial cells etc. There were, however, very few well differentiated mesenchymal cells. Thus hamartoma is an unlikely possibility since by definition it consists of an accumulation of mature cells normally present at that site. Stein et al $^{13}$ reviewed some lesions that showed electron microscopic evidence of proliferation of subendothelial reverse cells in response to varied intrinsic and/or extrinsic stimuli. Smooth muscle cell proliferation is well documented in experimental as well as human atherosclerosis. U1trastructural studies of thickened endocardium in cases of tetralogy of Fallot and thickened aortic cusps also revealed abundant proliferation of subendothelial mesenchymal cells.

Whether cardiac myxoma represents an unusual form of hyperplasia or a true neoplasm, it appears that this unique lesion arises from multipotential mesenchymal cells located in the subendocardium which, after proliferation, are capable of differentiating into various types of connective tissue cells. ${ }^{2), 4)-9), 13), 14), 26 \text { ! }}$

\section{REFERENCES}

1. Hudson REB: Cardiovascular Pathology, Vol 2, E Arnold Ltd, London, p 1567, 1965

2. Fisher ER, Hellstrom HR: Evidence in support of the neoplastic nature of cardiac myxoma. Am Heart J 60: 630, 1960

3. Vanden Berg C, Block APR: Myxoma cordis. Some morphological and enzyme histochemical aspects. Path Europ 1: 3, 1966

4. Fine G, Morales A, Horn RC Jr: Cardiac myxoma. A morphologic and histogenetic appraisal. Cancer 22: 1156, 1968

5. Matsuyama K, Ooneda G: Histogenesis of primary myxoma of the heart. A case report. Gann 58: 435, 1967

6. Merkow LP, Kooros MA, Magovern G, Hayeship DW, Weikers NH, Pardo M, Fisher DL: Ultrastructural features of a recurrent endothelial myxoma of the left atrium. Arch Pathol 93: 219,1972

7. Kelly M, Bhagwat AG: Ultrastructural features of a recurrent endothclial myxoma of the left atrium. Arch Pathol 93: 219, 1972

8. Ferrans VJ, Roberts WC: Structural features of cardiac myxomas. Histology, histochemistry and electron microscopy. Human Pathol 4: 111, 1973

9. Feldman PS, Horvath E, Kovacs K: An ultrastructural study of 7 cardiac myxomas. Cancer 40: 2216,1977 
10. Salyer WR, Salyer DC: Myxoma like features of organizing thrombi in arteries and veins. Arch Pathol 99: 307, 1975

11. Salyer WR, Page DL, Hutchins M: The development of cardiac myxomas and papillary endocardial lesions from mural thrombus. Am Heart J 89: 4, 1975

12. Chopra P, Sharma VK: Left atrial myxoma. A morphologic and histogenetic study. Jpn Heart J 22: 353, 1981

13. Stein AA, Mauro J, Thibodeau L, Alley $\mathbf{R}$ : The histogenesis of cardiac myxomas; relation to other proliderative diseases of subendothelial vasoformative reserve cells. in Pathology Annual, Vol 4, ed by Sommers SC, Appleton Centruary Crofts, New York, p 293, 1969

14. Silverberg SG, Kay S: Ultrastructure of a cardiac myxoma. Am J Clin Pathol 54: 650, 1970

15. Movat HF, Fernando NVP: The fine structure of connective tissue. I. The fibroblast. Exp Mol Pathol 5: 509, 1962

16. Ischikawa $\mathbf{H}$, Bischoff $\mathbf{R}$, Holtzer $\mathbf{H}$ : Formation of arrowhead complexes with heavy meromyosin in a variety of cell types. J Cell Biol 43: 312, 1969

17. Fine F: Neoplasms of the pericardium and heart. in Pathology of the Heart and Blood Vessels, ed by Gould SE, Charles C Thomas, Springfield, Illinois, p 851, 1968

18. Lippa S, Kahn LB, Reddick RL: The myofibroblast. in Pathology Annual, Vol 1, ed by Sommers SC, Rosen PP, Appleton Centruary Crofts, New York, p 409, 1980

19. Zuidema GD, Burke JF, Villagas AH, Scannell JG: Surgery of atrial myxoma. New Engl J Med 264: 1016, 1961

20. Williams WJ, Jenkins D, Erasmus D: The ultrastructure of cardiac myxoma. Thorax 25: 756,1970

21. Lannigan RA, Zaki SA: Ultrastructure of the normal endocardium. Br Heart J 28: 785, 1966

22. Becker CG, Murophy GE: Demonstration of contractile protein in endothelium and cells of the heart valves, endocardium, intima, atherosclerotic plaque and Aschoff bodies of rheumatic heart disease. Am J Pathol 55: 1, 1969

23. Symbas PN, Galambos JT, Sybers RG: Experimental left atrial thrombus and human left atrial myxoma. J Surg Res 12:8, 1972

24. Glasser SP, Bedynek JL, Hall RJ, Hopeman AR, Treasure RL, McAllister HA, Esterly JA, Manion WC, Stanford HS: Left atrial myxoma. Am J Med 50: 113, 1971

25. Bashey RI, Nochumson S: Cardiac myxoma. Biochemical analyses and evidence for its neoplastic nature. NYSJ Med 79: 29, 1979

26. Lee KT, Lee KJ, Lee SK, Imai H, O'Neal RM: Poorly differentiated subendothelial cells in swine aortas. Exp Mol Pathol 13: 118, 1970 